\title{
Micromorphology of the springbok louse Damalinia (Tricholipeurus) antidorcus found at the Rietvlei Nature Reserve near Pretoria, South Africa
}

\section{M.L. TURNER}

Turner, M.L. 2006. Micromorphology of the springbok louse Damalinia (Tricholipeurus) antidorcus found at the Rietvlei Nature Reserve near Pretoria, South Africa. Koedoe 49(1): 79-84. Pretoria. ISSN 0075-6458.

This report provides additional information on the morphology of Damalinia (Tricholipeurus) antidorcus, previously described only by light microscopy. Live lice were collected and prepared for viewing by SEM. Micromorphological features investigated included aspects of the forehead, mandibles and spiracles. The average length of the males was $2.0 \mathrm{~mm}$ and females $2.04 \mathrm{~mm}$. The anterior hyalin region of the head was notably emarginated. A well-developed medial groove on the ventral surface of the head between the mandibles was noted. The surface of the epipharynx was smooth. The labrum with its typical scale-like appearance gradually changed into the pulvinal area of the clypeus. Both genders had notched left mandibles. The mandibles were highly serrated on the oral surfaces. Situated ventrally below and caudal to the mandibles were a pair of labial palpi. The immediate area between, and surrounding the labial palpi was littered with numerous spiked setae and two well developed larger setae raised at their bases. The tips of the palpi bore three larger and longer sensory setae. Palpi of this nature are described here for the first time in $D$. antidorcus.

Key words: ectoparasites, lice, springbok.

M.L. Turner, Electron Microscope Unit, Medunsa Campus, University of Limpopo, 0204 Republic of South Africa.

\section{Introduction}

The springbok (Antidorcas marsupialis) is found in many reserves and game farms in South Africa. Ledger (1980) recorded Damalinia (=Tricholipeurus) (Bedford1931) antidorcus as a common ectoparasite (Mallophagean) of the springbok (Fig. 1). Few of the parasitic lice species have been described using the scanning electron microscope (SEM) and only line diagrams of the first description of $D$. antidorcus by Bedford (1931) and an insert of a second sketch after Werneck (1950) as recorded by Ledger (1980) were found in an extensive literature search. These diagrams were drawn from light microscope (LM) images obtained from the technology of the early twentieth century during 1931. This study was performed to serve as an aid in the identification of $D$. antidorcus and to add to the existing detail found on its morphology.

The superorder Psocodea comprises two orders, one of which is the Phthiraptera. Phthiraptera have no free-living stages and are all obligate ectoparasites found on almost all avians and approximately a quarter of all mammals (Smith 2000; Soler Cruz 1995). Lice are further divided into four suborders namely Amblycera, Ischnocera, Rhyncophthirina (a monogeneric group found on elephants and warthog only) and Anoplura. Amblycera and Ischnocera are of the biting (Mallophaga) type whilst the latter (Anoplura) are commonly known as the sucking lice (Smith 2000). The genus Damalinia comprises three subgenera (Soler Cruz \& Martin Mateo 1998,): D. tricholipeurus, D. cervicola and D. damalinia (Bovicola, Ledger 1980). 


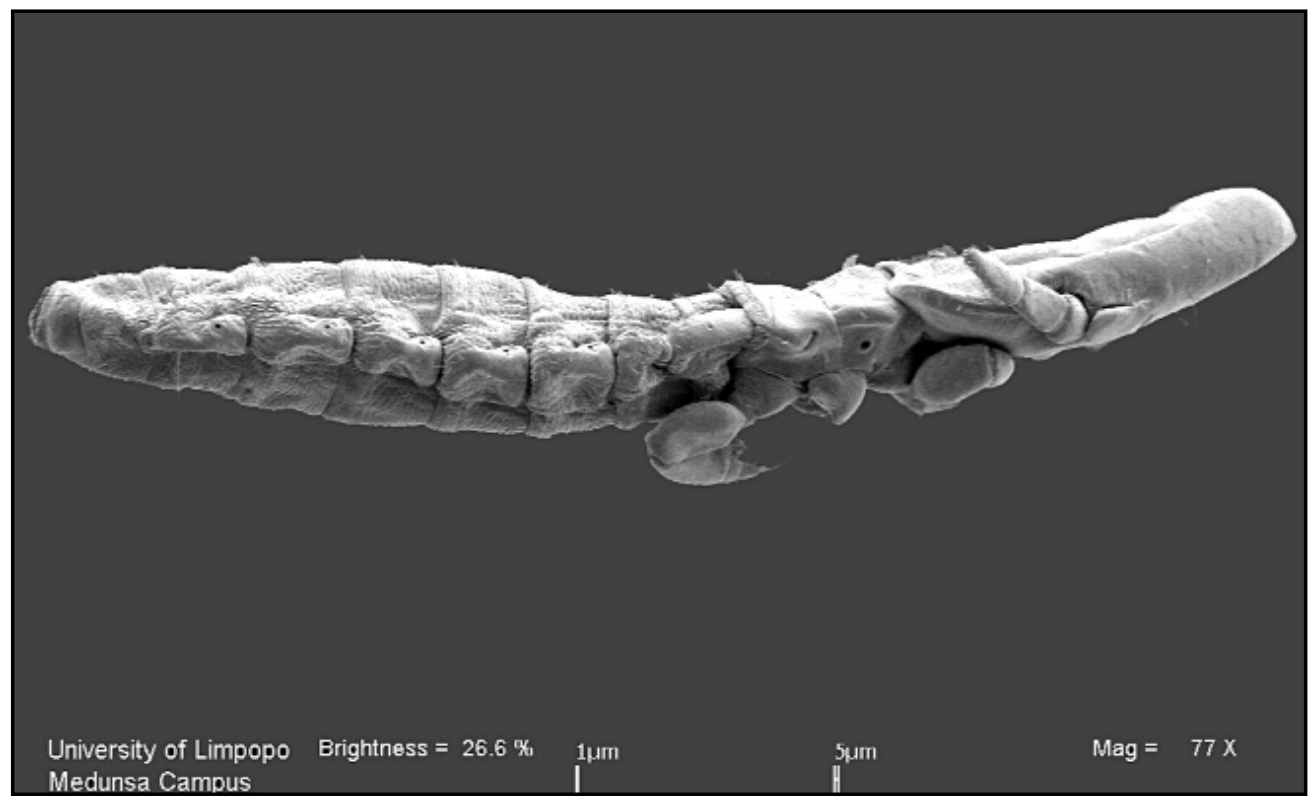

Fig. 1. A low magnification SEM micrograph of the lateral view D. antidorcus.

\section{Materials and methods}

Live lice were collected from springbok in the Rietvlei Nature Reserve situated to the south east of Pretoria during an organised culling session. The springbok were healthy and not heavily infested, thus only six female lice, in varying stages of maturity, and two males were found in the area around the base of the ear. The specimens were processed for scanning electron microscopy as described by Turner et al. (2004) and viewed in a Leica 420 Stereoscan.

\section{Results}

The SEM investigation revealed several micromorphological specialisations not previously demonstrated in Bedford's (1931) light microscopically derived line diagrams or description of $D$. antidorcus. The following specialisations were revealed when the lice were viewed in the scanning electron microscope:

The total average length of the males was $2.0 \mathrm{~mm}$ versus $2.04 \mathrm{~mm}$ for females, a deviation $(0.02 \mathrm{~mm})$ that was barely notable to the above-mentioned measurements. This slight deviation could be ascribed to the difference in the resolving power of the lightand electron microscopes and likely due to the small number of lice collected. The ventral surface of the head clearly demonstrated the structures of the preantennal regions such as ventral carina, pulvinus, labrum, mandibles and clypeus (Turner 2003) (Fig. 2). The anterior hyalin region of the head was notably emarginated. A welldeveloped medial groove on the ventral surface of the head between the mandibles was noted (this groove fits snuggly over the host's hairs and probably also facilitates attachment) (Turner et al. 2002). The labrum that lies within the medial groove, appeared to be well developed and was found anterior to, and above the mandibles. Its scale-like surface flowed with a gradual changeover into the smooth pulvinal area of the clypeus (Fig. 3). In both genders, the left mandibles were notched on the cutting edges (Fig. 4). This could aid in rasping the skin and scraping up epidermal exfoliation during feeding. The left and right mandibles were serrated on the oral surfaces (Fig. 5) especially 


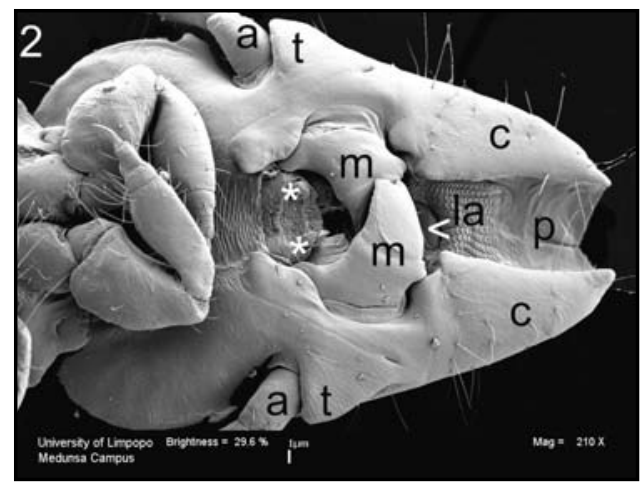

Fig. 2. The ventral aspect of the head, (a) first antennal segment, (c) clypeus, (la) labrum, (m) mandibles, (p) pulvinus, (t) trabecular region, (arrow) epipharynx, (*) labial palpi.

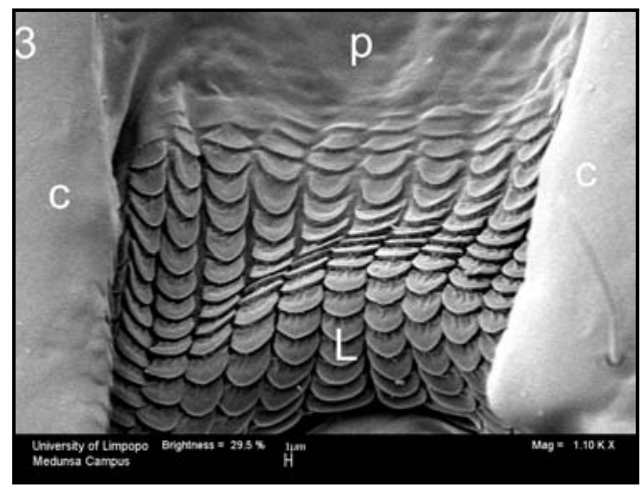

Fig. 3. An enlarged view of the labrum (L) showing the gradual structural changeover to the pulvinus (p). (c) = clypeal border.

notable when viewed laterally. The ridged serrations probably facilitate attachment to the host's hair, especially in extreme circumstances such as when the springbok seeks refuge whilst running in dense tall grassy areas, during life threatening situations. Situated ventrally below and caudally to the mandibles were a pair of labial palpi. The immediate area between, and surrounding the labial palpi contained numerous spinelike, spiked setae and two well developed larger, flexible setae, which were raised at their bases. The spiked setae were similar to the epipharyngeal dentate structures found in the blesbuck louse Damalinia crenelata

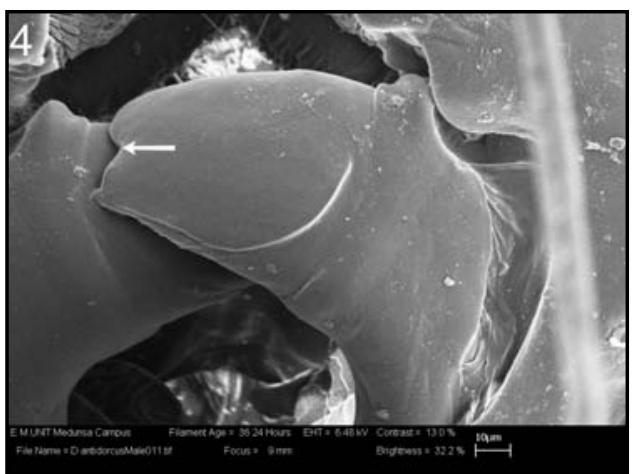

Fig. 4. SEM of the mandible showing the notched cutting edge (arrow).

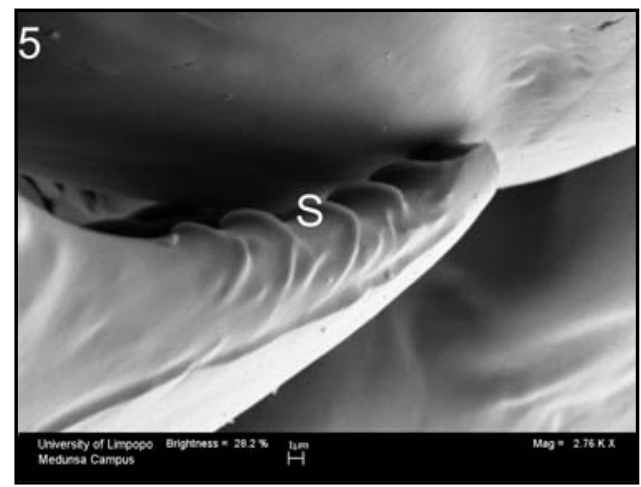

Fig. 5. A high magnification of the oral surface of the right mandible where (s) represents the serrated surface.

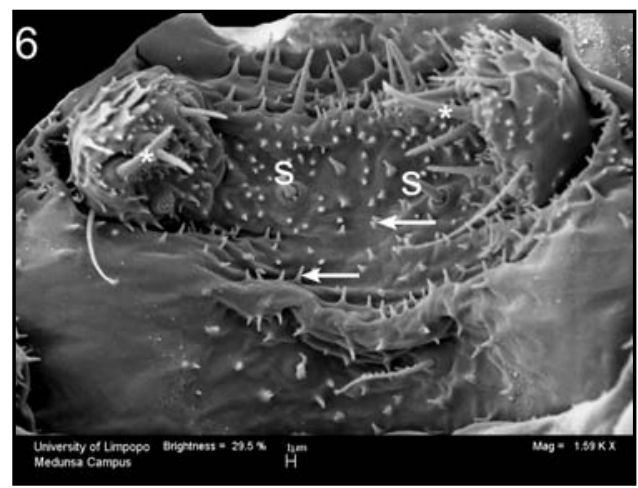

Fig. 6. The pair of labial palpi with numerous spiked or spinous setae (arrows) and two well developed larger sensory setae (s), which are raised at their bases. The tips of the palpi bore three larger and longer sensory setae $(*)$. 


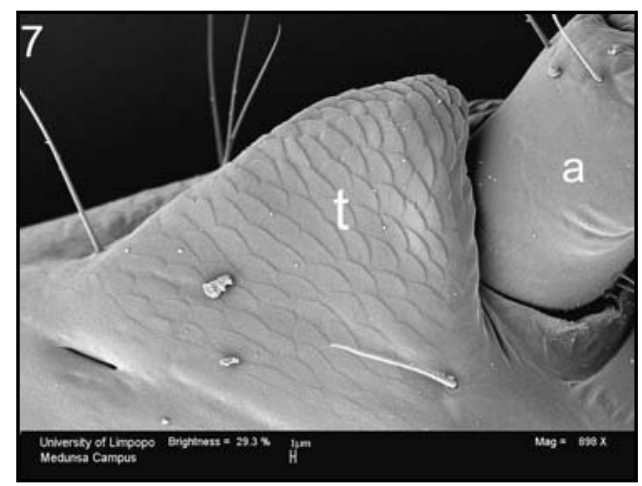

Fig. 7. The triangular trabeculum (t). (a) = antenna.

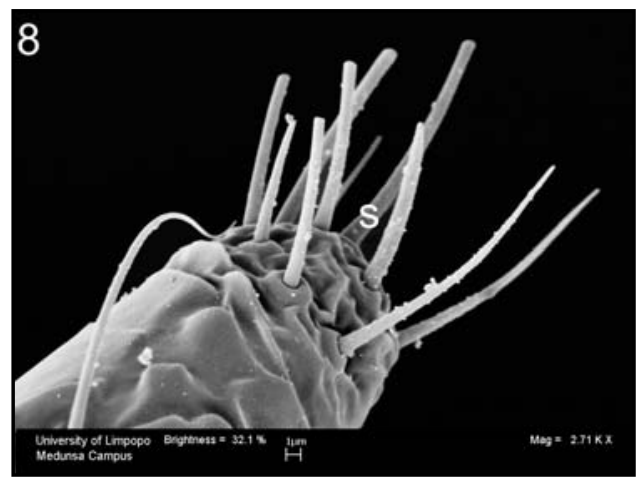

Fig. 8. The distal tip of the antennae constituted 10 apical setae (s).

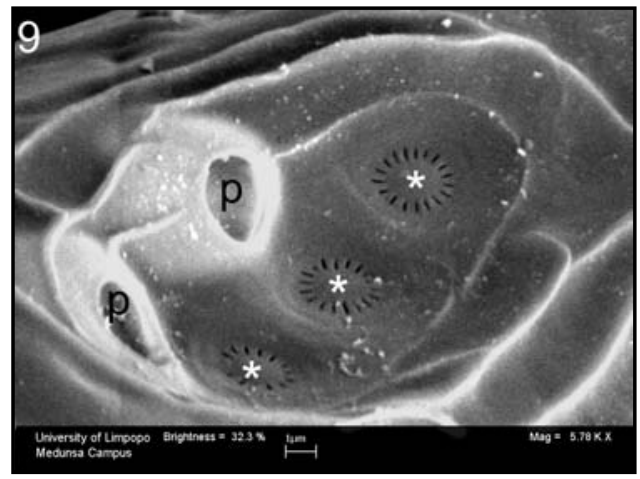

Fig. 9. The 2 pore organs (p) with three plate organs showing the characteristic radiating pattern of slitlike openings.
(Turner 2003) whereas the surface of the epipharynx was smooth in $D$. antidorcus. The tips of the palpi bore three larger and longer sensory setae. Palpi of this nature were described here for the first time in $D$. antidorcus (Fig. 6).

The three segmented antennae were directed caudally and showed thick, short, robust first segments in the male whilst the first segments in the female were much shorter and thinner. The first segment was well protected by a protruding trabeculum (Fig. 7). The shape of the trabeculum was sexually dimorphic, as that of the male was more acutely angled and more caudally directed than that of the female. The well-developed peg organ (sensilla basoconica) on the distal tip of the antennae consisted of 10 apical setae which varied in length (Fig. 8). Antennal tuft organs (sensillae coeloconica) were absent within the two pore organs. Adjacent to the pore organs were three plate organs, with their characteristic radiating pattern of slitlike openings (Fig. 9). Unlike the plate organs found on B. caprae (Sebei et al, 2004), a louse infesting goats, which are surrounded by individually raised skeletal plates, those of $D$. antidorcus were each encompassed in a single plate. This could be of taxonomic importance during SEM investigations as these characteristics are not visible under the light microscope. The prothorax and mesothorax were clearly distinguishable. The posterior edge of the mesothorax showed some sexual dimorphism in that the male (Fig. 10), had a regular transverse row or fringe of seta on, and overlapping, the posterior margin whereas the row of setae in the female (Fig. 11) was irregularly arranged and situated notably further from the margin. The edge was straight in the male whilst more rounded and pointed in the female. Added dimorphism in the same figures, was the slight variation in the posterior parietal area of the edge of the dorsoventrally flattened head. These sexual dimorphic features are recorded here for the first time in $D$. antidorcus. Two thoracic spiracles were noted (Fig. 12). Each was situated laterally on the left and right side of the mesothorax. The spiracles were well 

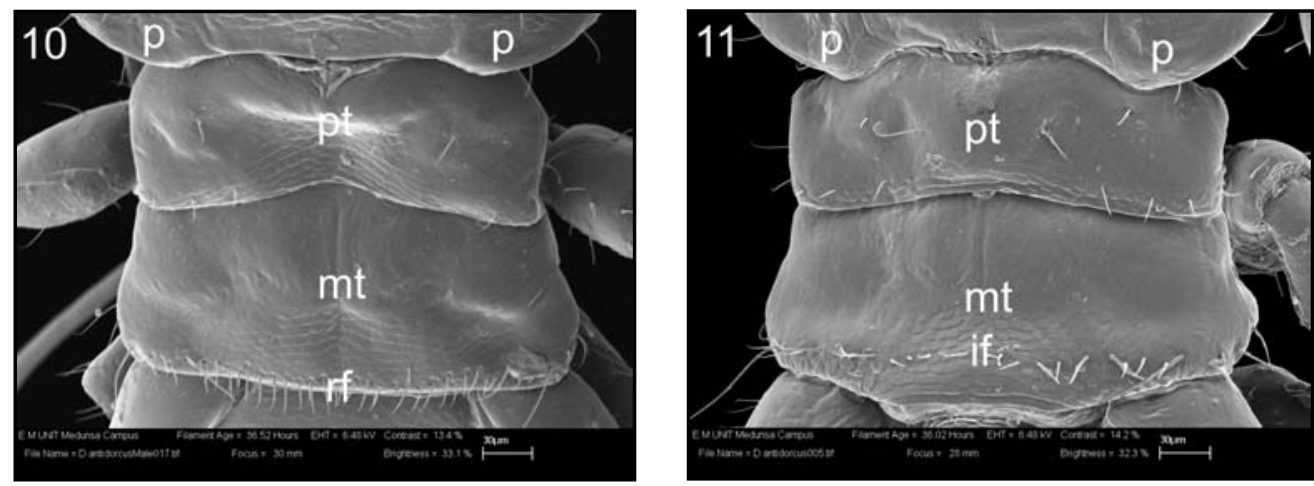

Fig. 10 \& 11. The posterior edge of the meso-thorax (mt) of the male with its regular transverse fringe (rf) of seta and the dimorphic difference in the female respectively. $(\mathrm{p})=$ parietal area, $(\mathrm{pt})=$ pro-thorax, (if) $=$ irregular fringe.

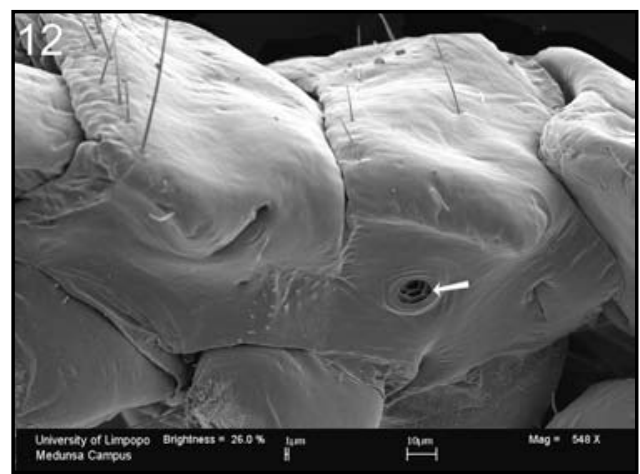

Fig. 12. The thoracic spriracle (arrow).

developed. The spiracular lumen was lined with regular circular disc-shaped structures intersected with trabecular divisions that could probably be likened to the mammal pharynx with its cartilage rings (Fig. 13). Previous literature suggests that these 'pharyngeal' discs and 'trabeculae' filter the air during discontinuous respiration and prevent dust particles and other debris from entering (Turner 2004). Literature reviews did not reveal any terminology for the filtering apparatus as described above. The typical Damalinean legs showed extended claws which closed towards fixed, appositional but shorter, thumbs on the distal ends of the tibiae.

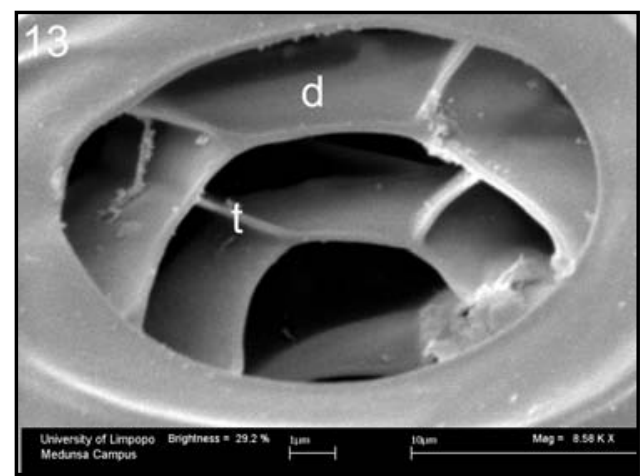

Fig. 13. The spiracular lumen was lined with regular circular disc-shaped (d) structures, intersected by trabecular (t) divisions.

According to Bedford (1931), the mid tibia was narrower and longer than the fore or hind tibiae. Six pairs of abdominal spiracles were present whilst the second segment only showed a stigmatal scar with no spiracle. (Fig. 14 a \& b). The female genitalia were underdeveloped and not worthy of discussion in this study whilst the male parameres only protruded slightly (Fig. 15).

A comparative investigation on different species of the same genus will be performed in the near future. No other remarkable micromorphology was noted. This investigation does not purport to be taxonomic in 


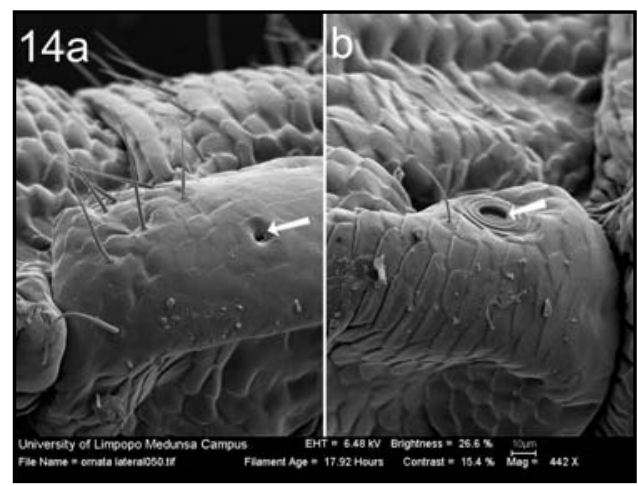

Fig. 14 a \& b. Six pairs of abdominal spiracles (Fig. b) (arrow) were present whilst the second segment only showed a stigmatal scar (Fig. a) (arrow).

nature but was rather intended to assist biologists and veterinarians in the identification of the species and in comparative studies.

\section{Acknowledgements}

Riaan Marais the manager of the reserve, Cecil Labuschagne for his unselfish contribution during specimen collection. Toekie Kleynhans at the reception office of Rietvlei Nature Reserve, for always being so friendly and polite. The Friends of Rietvlei for the use of their facilities.

\section{References}

BEDFORD, G.A.H. 1931. New genera and species of Mallophaga. Report of the Director of Veterinary Services and Animal Industry 17: 283-297.

LEDGER, J.A. 1980. Publications of the South African Institute for Medical Research: The Arthropod parasites of Vertebrates in Africa south of the Sahara, Phthiraptera (Insecta). Johannesburg: South African Institute for Medical Research. (Publications of the South African Institute for Medical Research no. 56) Funny place for a bracket to close 4: 196-296.

Sebei, P.J., C.M.E. McCrindLe, E.D. Green \& M.L. TURNER. 2004. Use of SEM to confirm the iden-

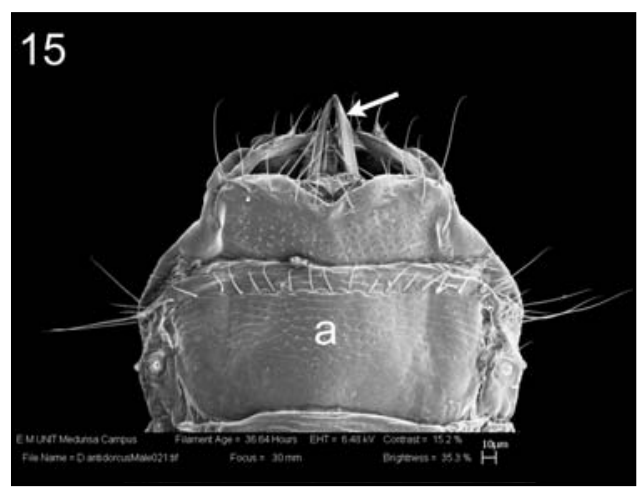

Fig. 15. The male genital area $($ arrow $)=$ parameres, (a) = abdomen.

tity of lice infesting communally grazed goat herds. Onderstepoort Journal of Veterinary Research 71: 87-92.

SMITH, V.S. 2000. Avian louse phylogeny (Phthiraptera: Ischnocera): A cladistic study based on morphology. PhD thesis, University of Glasgow.

SolER CRUZ, M.D. 1995. Antennal sense organs of Phthiraptera (Insecta). Scanning electron microscopy of several species of Anoplura. Micron 26(1): 7-14.

Soler Cruz, M.D. \& M. Mateo. 1998. Sensory equipment of the antennal flagellum of several species of Damalinia (Phthiraptera: Thrichodectidae). Micron 29(6): 431-438.

Turner, M.L., C. Baker \& R. Marais. 2002. A scanning electron microscope investigation of the waterbuck louse Bovicola hilli found at the Reitvlei Nature Reserve. Koedoe 45(1): 59-63.

TURNER, M.L. 2003. The micromorphology of the blesbuck louse Damalinia (Damalinia) crenelata as observed under the SEM. Koedoe 46(1): 65-71

Turner, M.L., C. Labuschagne \& E.D. Green. 2004 The morphology of the African buffalo louse Haematopinus bufali as observed under the SEM. Koedoe 47(2): 83-90.

USDA, 1970. Chewing and sucking lice as parasites of mammals and birds. United States Department of Agriculture. (Technical Bulletin; no. 1849.) 